\title{
BMJ Open Biomechanical reposition techniques in anterior shoulder dislocation: a randomised multicentre clinical trial - the BRASD-trial protocol
}

\author{
David N Baden, ${ }^{1}$ Martijn H Roetman, ${ }^{2}$ Tom Boeije, ${ }^{1}$ Floris Roodheuvel, ${ }^{2}$ \\ Nieke Mullaart-Jansen, ${ }^{1}$ Suzanne Peeters, ${ }^{2}$ Mike D Burg ${ }^{3}$
}

To cite: Baden DN, Roetman MH, Boeije T, et al. Biomechanical reposition techniques in anterior shoulder dislocation: a randomised multicentre clinical trial- the BRASD-trial protocol. BMJ Open 2017;7:e013676. doi:10.1136/ bmjopen-2016-013676

- Prepublication history for this paper is available online. To view these files please visit the journal online (http://dx.doi. org/10.1136/bmjopen-2016013676).

DNB and MHR contributed equally.

Received 1 August 2016 Revised 7 April 2017 Accepted 10 April 2017

CrossMark

${ }^{1}$ Emergency department Westfriesgasthuis Hoorn, Hoorn, The Netherlands

${ }^{2}$ Emergency department,

Flevoziekenhuis Almere, Almere, The Netherlands

${ }^{3}$ UCSF/Fresno, Fresno, California USA

Correspondence to David N Baden; dnbaden@ gmail.com

\section{ABSTRACT}

Introduction Glenohumeral (shoulder) dislocations are the most common large joint dislocations seen in the emergency department (ED). They cause pain, often severe, and require timely interventions to minimise discomfort and tissue damage. Commonly used reposition or relocation techniques often involve traction and/ or leverage. These techniques have high success rates but may be painful and time consuming. They may also cause complications. Recently, other techniques-the biomechanical reposition techniques (BRTs) - have become more popular since they may cause less pain, require less time and cause fewer complications. To our knowledge, no research exists comparing the various BRTs. Our objective is to establish which BRT or BRT combination is fastest, least painful and associated with the lowest complication rate for adult ED patients with anterior glenohumeral dislocations (AGDs).

Methods and analysis Adults presenting to the participating EDs with isolated AGDs, as determined by radiographs, will be randomised to one of three BRTs: Cunningham, modified Milch or scapular manipulation. Main study parameters/endpoints are ED length of stay and patients' self-report of pain. Secondary study parameters/endpoints are procedure times, need for analgesic and/or sedative medications, iatrogenic complications and rates of successful reduction. Ethics and dissemination Non-biomechanical AGD repositioning techniques based on traction and/or leverage are inherently painful and potentially harmful. We believe that the three BRTs used in this study are more physiological, more patient friendly, less likely to cause pain, more time efficient and less likely to produce complications. By comparing these three techniques, we hope to improve the care provided to adults with acute AGDs by reducing their ED length of stay and minimising pain and procedure-related complications. We also hope to define which of the three BRTs is quickest, most likely to be successful and least likely to require sedative or analgesic medications to achieve reduction. Trial registration number NTR5839.

\section{INTRODUCTION}

We observed that commonly used anterior glenohumeral dislocation (AGD) repositioning techniques using traction and/ or leverage inflicted pain required time-consuming pain relief interventions and were not always effective. A comprehensive literature search was done to identify alternate repositioning techniques.

\section{Epidemiology}

Glenohumeral dislocations commonly present to the emergency department (ED) ${ }^{1}$ and are generally due to sports-related trauma, falls, motor vehicle accidents and, rarely, seizures. ${ }^{2-9}$ Minor 'trauma' (such as rolling over in bed) can cause dislocations in those with unstable shoulders. The median age range for dislocations in men is 25-30 years and 50-70 years in women, with an overall male-to-female ratio of 2.6-3.6:1. ${ }^{2310-14}$ Anterior dislocations are most common $(93 \%-97 \%)$, followed by posterior $(1 \%-4 \%)$ and inferior (luxatio erecta) $(0.5 \%-2 \%){ }^{213-16}$ Since the $1980 \mathrm{~s}$, the incidence of glenohumeral dislocations has increased, from 5.3 to 26 per $100000 .^{231012141517}$

\section{Anatomy}

The glenohumeral joint consists of the small scapular glenoid fossa and a relatively large humeral head. This inherently unstable joint is stabilised by four rotator cuff muscles. In AGDs, the supraspinatus, infraspinatus and teres minor muscles stretch and spasm, causing pain. It is theorised that spasm of the long head of the biceps brachii muscle acts as a 'bowstring,' keeping the humeral head out of the glenoid fossa. As a result, the patient with AGD presents generally with a painful, manually fixed, slightly externally rotated and abducted arm. ${ }^{18}$

In AGD, it is common medical practice to perform reduction quickly, to reduce pain and minimise complications. ${ }^{19}$ Successful repositioning occurs when normal glenohumeral 
anatomy is restored. The patient often experiences this as decreased discomfort, recovery of function and a feeling that 'the shoulder is normal'.

\section{Reduction techniques}

More than 50 glenohumeral dislocation repositioning techniques exist. They are described unambiguously in the literature but often inconsistently performed in clinical practice. ${ }^{21}{ }^{22}$ The wide range of techniques can be divided into three groups based on their major mode of action: traction, leverage or biomechanical. ${ }^{8} 18$ 21-24 The most commonly used techniques in Dutch EDs are the traction-based Hippocratic method and the leverage-based Kocher method. ${ }^{4}$

\section{Traction-based techniques}

Traction-based techniques-such as the Hippocratic method and its variants-rely on force to overcome muscle spasm. The idea being that, by applying traction, muscles will tire and relocation will occur. The amount of traction the operator can apply can be increased by means of countertraction. Many modifications of the pure Hippocratic method exist, some already suggested by Hippocrates himself, including the application of countertraction with a sheet, the operator's shoulder, the operator's knee, the patient's bodyweight (Eskimo technique), a bed, a chair and a ladder. ${ }^{21-23} 25-37$ Since applying traction will increase muscle spasm and pain, traction techniques often require analgesia and/or sedation, ${ }^{22} 3238-41$ resulting in prolonged ED lengths of stay (LOSs). ${ }^{9}$ Traction-countertraction techniques may result in neurovascular damage in the axillary region, although incidence is unknown. ${ }^{22} 2342$

\section{Leverage-based techniques}

Kocher's method, originally described in 1870 , is the best-known leverage technique for AGD reduction. ${ }^{43}$ The technique has been altered by clinicians since, and often includes traction, which is commonly associated with increased pain. ${ }^{22} 293844-46$ This combined technique achieves good results, but some force is still needed to manipulate the humeral head over the glenoid. ${ }^{824044478}$ Additionally, iatrogenically induced humeral fractures and axillary vessel ruptures are seen with the technique and were, in fact, described by Kocher in his original article. ${ }^{22} 29464950$ Two other studies describe the risk of postreduction humeral neck fractures during leverage techniques in patients over 40 years of age. ${ }^{51} 52$

\section{Biomechanical techniques}

More recently, several techniques with a biomechanical basis have been described. These biomechanical repositioning techniques (BRTs) depend on muscular relaxation without force and often start with the patient's arm in an analgesic position, thus eliminating or minimising the need for sedatives or analgesics. They do require patient cooperation, making it essential that patients receive accurate instruction about the procedure.$^{53}$ BRTs can be separated into three approaches: positioning and relaxation, zero position and scapular manipulation.

The Cunningham technique involves positioning and relaxation. The patient's arm must be fully adducted for the technique to succeed. This reduces spasm in the stretched rotator cuff muscles. By massaging the trapezius, the deltoid and especially the biceps brachii muscles, tension in the 'bowstringed' biceps brachii will decrease and relocation will occur. No traction is applied..$^{54}$

The original Milch technique first described in 1938 and the modified Milch technique described in 1992 involve positioning the patient's arm such that all the muscles acting on the shoulder joint align with the humerus (the so-called 'zero position'). ${ }^{4455}$ No traction is applied.

The scapular manipulation technique (SMT) was developed in the late 1970s and published in 1982. ${ }^{556}$ As the name implies, SMT involves scapular movement with the patient prone so that the glenoid fossa re-engages the humeral head, achieving reduction. In a sense, arm traction is involved as well, but only to stabilise the humeral head, not to fatigue muscles. Patient pain is thereby limited. The classically described SMT is often modified to a sitting or supine position. ${ }^{23}$

\section{Pain relief}

Many methods exist to address the pain associated with AGD, ranging from intra-articular anaesthesia to nitrous oxide, nerve blocks and various procedural sedation and analgesia regimens. ${ }^{57-75}$ Not one method is clearly superior in every regard, and all involve time to gather medications, consent the patient, administer (and possibly re-administer) medications, wait for effects and observe the patient postprocedure as he/she recovers. ${ }^{162-6871-747677}$ In addition to these delays and the possibility of inadequate pain relief, there is the real risk of complications associated with procedural sedation: nausea and vomiting, hypotension, hypoxaemia, prolonged drowsiness, headache, aspiration, respiratory depression and untoward medication reactions, among others. ${ }^{58} 6264656769-74$ Many authors have advocated that the best relief for AGD pain is reduction. ${ }^{8} 9473$

\section{Conclusion}

A variety of traction-based or leverage-based techniques are often successful in repositioning AGDs, with success rates ranging from $60 \%$ to $100 \%$ in generally small studies. ${ }^{22}$ However, since pain is increased by traction, countertraction and leverage, these techniques often require the administration of analgesics and sedations, which may be associated with complications. Additionally, the techniques themselves may not be quick, painless or complication free and do not pay heed to patient satisfaction or ED throughput. ${ }^{18}$ Consequently, total ED time can be 3 hours or more for a procedure with a performance time of less than 10 min. ${ }^{2459} 63-687172747578$

In contrast, BRTs do meet the requirements for optimal repositioning. ${ }^{7919} 2353-567980$ 'The ideal method should be simple, easy, quick, effective, atraumatic and pain 
free; require little assistance or medication; and cause no additional injury to the shoulder joint or to the musculoskeletal or neurovascular structures'.

Data on the BRTs are scarce, but the reported minimal inflicted pain, high success rates and the avoidance or reduced need for sedation or analgesia seem promising for a shorter ED stay, lower resource utilisation and a better patient experience. ${ }^{9}{ }^{79}$ However, which BRT or BRT combination is fastest, least painful and least likely to cause complications is unaddressed in the current medical literature.

\section{METHODS AND ANALYSIS}

\section{Primary research question}

Which BRT or BRT combination is fastest and least painful for adult ED patients with AGDs?

\section{Secondary research questions}

- Are complications caused by BRTs or BRT combinations? If so, what are those complications?

- What are the reposition success rates of the BRTs or BRT combinations?

- What are the ED LOSs associated with the BRTs or BRT combinations?

\section{Study design}

A randomised controlled trial (RCT) will be conducted in two Dutch hospital-based EDs comparing the three BRTs: modified Milch, Cunningham and SMT. ${ }^{23} 5354$

To optimise technique execution from study outset, we will train participating doctors, nurse practitioners (NPs) and nurses before the study starts. Visual and written instruction will be provided and learning materials will also be available online (see the Videos section).

\section{Patient recruitment}

Adults presenting acutely to the two study centre EDs with isolated AGDs demonstrated on standard shoulder radiographs will be approached about study participation (Box 1 for inclusion/exclusion criteria). Written informed consent-including an opt-out path-will be obtained from all patients. The study commenced 1 August 2016 and will recruit patients for 2 years.

\section{Box 1 Inclusion/exclusion criteria}

\section{Inclusion \\ - All adult patients ( $\geq 18$ years) with an isolated anterior glenohumeral dislocation of less than 24 hours and able to understand and sign consent}

\section{Exclusion criteria}

A potential subject who meets any of the following criteria will be excluded from participation in this study:

- subcapital humeral fractures-major multi-trauma

- subclavicular, intrathoracic, inferior or posterior dislocations

- dislocations presenting after 24 hours.

\section{Investigational treatment}

Patients able to adduct ('can adduct' path) will be randomised to BRT using Cunningham, modified Milch or SMT. Those unable to adduct ('cannot adduct' path) will be randomised to BRT using either modified Milch or SMT (see figure 1 flowchart).

AGD reduction will be defined as the re-establishment of a normal glenohumeral relationship on postintervention radiographs. After reduction, an internal rotation sling will be applied and follow-up arranged in the outpatient clinic.

\section{Data collection}

Baseline demographics, medical history and study-specific data will be collected. ED LOS will be defined as the time in minutes from patient arrival in the ED until discharge. The well-validated Numeric Rating Scale of $0-10$ will be used to assess patients' pain, before, during and after reduction attempts.

Other data to be collected:

- reduction time (in minutes, from start to end of procedure)

- number of reduction techniques used

- sedatives and analgesics used (types, dosages, prehospital and/or in-hospital administration)

- preintervention and postintervention radiograph interpretation

- physical examination (with particular attention to neurovascular status of the affected arm)

- iatrogenic complications (caused by the interventions)

- patient age

- patient gender

- time of last oral intake

- dislocation number (first or recurrence number)

- dislocation mechanism (sports, seizures, falls, traffic accidents, other).

\section{Statistical methodology}

We calculated the sample size on ED LOS per combination of techniques as shown in figure 1. A 15-minute difference between the combinations of techniques is considered clinically relevant. We assumed a probability of type 1 (alpha) error of 0.05 and a type 2 (beta) error probability of 0.20 .

In the cannot adduct group, we will compare two combinations of techniques. Assuming non-normality and using the Mann-Whitney $\mathrm{U}$ test, power calculations lead to a sample size per combination of 31 , with a total of 62 inclusions.

In the can adduct group, we will compare three combinations of techniques. Similar to the calculation of the cannot adduct group, assuming non-normality and using the Kruskal-Wallis test, power calculations lead to a sample size per combination of 41, with a total of 123 participants required.

One hundred and eighty-five inclusions are therefore needed in total. Based on other studies done at one of our hospitals, we are anticipating a $20 \%$ data loss, so we intend to enrol 222 patients. 


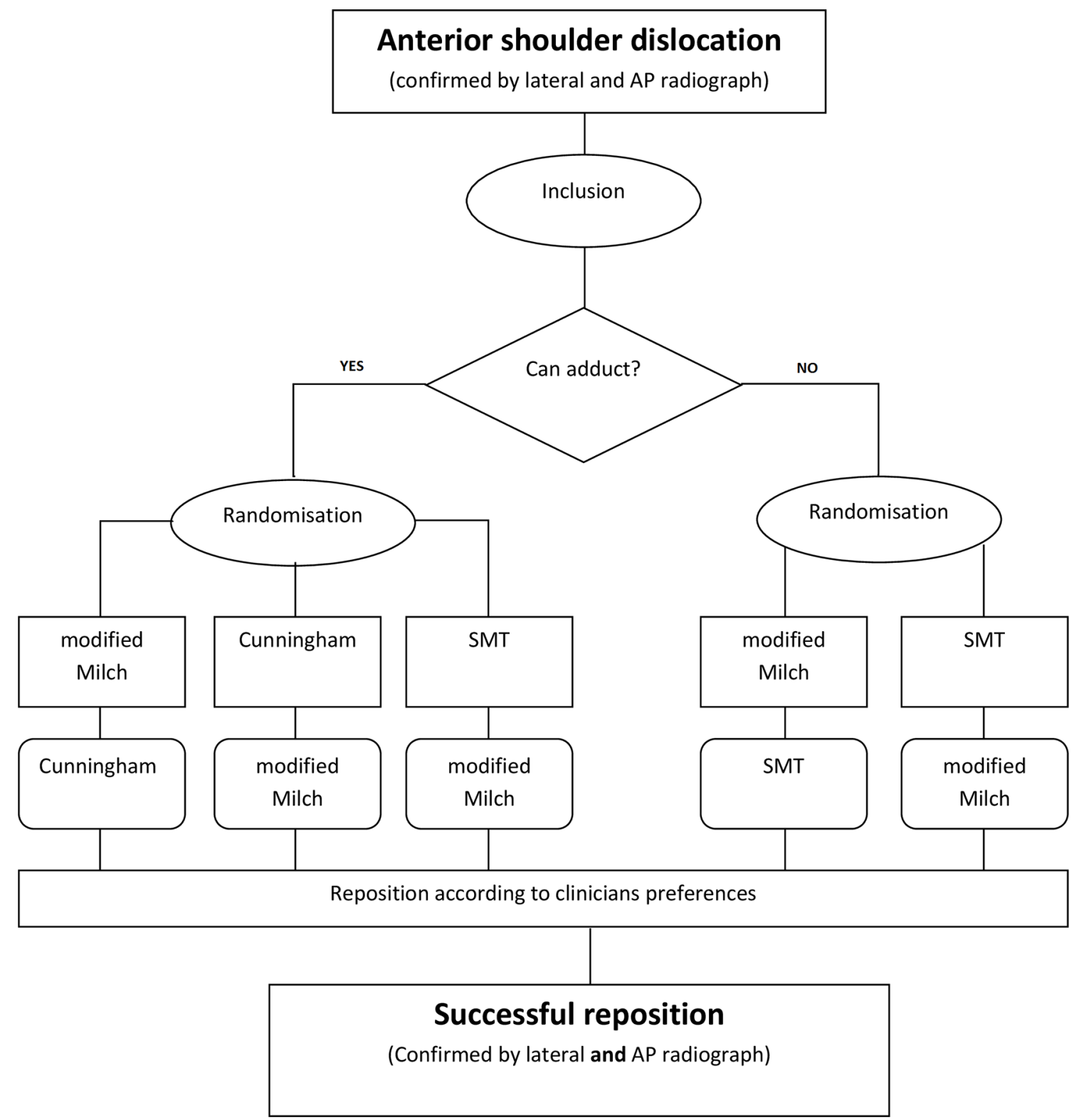

Figure 1 Flowchart showing the randomisation of the biomechanical reposition techniques in anterior shoulder dislocation trial. AP, anteroposterior view; SMT, scapular manipulation technique.

Enrolment will continue until the required sample size in each arm in reached.

The techniques will be randomised in advance per centre by creating a stratified block randomisation list.

Nominal variables related to subgroups will be analysed with the chi-square test. Ordinal variables related to subgroups will be analysed using the Mann-Whitney U test or the Kruskal-Wallis test. Variables will be compared with each other (depending on the scaling level) with the Wilcoxon test, the Friedman test and the correlation coefficient of Spearman. Nominal and ordinal variables will be described using frequency tables, mode and median. A value of $p<0.05$ will be accepted as statistically significant.

In cases of missing data, the treating physician will make inquiries. If more than $30 \%$ of the data are still missing postinquiry, the patient will be excluded from the study. SPSS V.22 will be used for data processing.

\section{ETHICS AND DISSEMINATION}

This RCT will compare three BRTs described in the medical literature, the modified Milch, Cunningham and the SMT, ${ }^{23} 5354$ and will be one of the first comparative studies on BRT outcomes. Its aim is to establish whether different BRTs produce different ED LOS and patient discomfort during and after reduction. This trial will add valuable information to the presently limited knowledge about these techniques. Results of the study will be made publicly available by submitting the results to a peer-reviewed medical journal. No veto or disclosures are made with the sponsors.

AGDs are painful and require timely intervention to relieve and/or minimise discomfort and potential tissue damage. Non-BRTs are based on traction or leverage and therefore inherently painful and potentially harmful. We posit that the BRTs used in our study 
are more physiological, likely less pain producing and will lead to a decreased ED LOS while being just as successful as older techniques at repositioning the acute AGD. To date, no adverse events have been described for these techniques. Our study results may help define a more standardised, less risky and improved treatment regimen for patients with AGD by minimising pain and shortening ED throughput times. This may not only benefit individual patients but also healthcare systems.

\section{LIMITATIONS}

Since it is impossible to blind physicians and patients to the technique used for shoulder reduction, this may introduce a bias toward techniques more favoured by some physicians. We are also aware that practitioner learning will occur over the course of the study and individual physicians may gravitate toward or become increasingly adept at certain techniques.

We will attempt to minimise the bias introduced by the absence of blinding, learning effect and optimise technique execution by training the participating doctors, NPs and nurses before the study starts. After the study start, we plan to revisit the participating centres to train and answer questions about the techniques used. Also, visual and written instructions will be provided at the start of the study and learning material is also be available on our YouTube channel.

\section{Videos}

1. Cunningham:https://youtu.be/6TF3h3RNS0M?t=10

2. Modified Milch:https://youtu.be/yOm1bF-U9Q8

3. SMT:https://youtu.be/Cig7XRH8cZs

Acknowledgements We thank Tjeerd van der Ploeg for statistical guidance and Sylvia van Rossum for her endless support.

Contributors DNB is the corresponding author. DNB and MHR were responsible for conception and study design and, as coordinators of project, coordination and writing of manuscript. TB, FR, NMj and SP were responsible for manuscript review and patient recruitment. SP was responsible for guidance in protocol design. MDB was responsible for manuscript writing, editing and study refinement/focus. DNB and MHR contributed equally to this work and are both first authors.

Competing interests None declared.

Ethics approval Approval for the BRASD-trial has been obtained from the ethics committee (MREC) Northern Holland. The BRASD-trial is conducted in accordance with the principles of Good Clinical Practice as defined by the International Council on Harmonisation (ICH-E6, 17/07/96) as well as with specific laws and regulations that apply in the Netherlands.

Provenance and peer review Not commissioned; externally peer reviewed.

Open Access This is an Open Access article distributed in accordance with the Creative Commons Attribution Non Commercial (CC BY-NC 4.0) license, which permits others to distribute, remix, adapt, build upon this work non-commercially, and license their derivative works on different terms, provided the original work is properly cited and the use is non-commercial. See: http://creativecommons.org/ licenses/by-nc/4.0/

(C) Article author(s) (or their employer(s) unless otherwise stated in the text of the article) 2017. All rights reserved. No commercial use is permitted unless otherwise expressly granted.

\section{REFERENCES}

1. Yang NP, Chen HC, Phan DV, et al. Epidemiological survey of orthopedic joint dislocations based on nationwide insurance data in Taiwan, 2000-2005. BMC Musculoskelet Disord 2011;12:253.

2. Taş M, Canbora MK, Köse Ö, et al. Demographic and clinical characteristics of traumatic shoulder dislocations in an urban city of Turkey: a retrospective analysis of 208 cases. Acta Orthop Traumatol Turc 2013;47:147-52.

3. Zacchilli MA, Owens BD. Epidemiology of shoulder dislocations presenting to emergency departments in the United States. $J$ Bone Joint Surg Am 2010;92:542-9.

4. te Slaa RL, Wijffels MP, Marti RK. Questionnaire reveals variations in the management of acute first time shoulder dislocations in the Netherlands. Eur J Emerg Med 2003;10:58-61.

5. Sparks SR, DeLaRosa J, Bergan JJ, et al. Arterial injury in uncomplicated upper extremity dislocations. Ann Vasc Surg $2000 ; 14: 110-3$.

6. Hovelius $L$. The natural history of primary anterior dislocation of the shoulder in the young. J Orthop Sci 1999;4:307-17.

7. Sayegh FE, Kenanidis El, Papavasiliou KA, et al. Reduction of acute anterior dislocations: a prospective randomized study comparing a new technique with the Hippocratic and Kocher methods. J Bone Joint Surg Am 2009;91:2775-82.

8. Amar E, Maman E, Khashan M, et al. Milch versus Stimson technique for nonsedated reduction of anterior shoulder dislocation: a prospective randomized trial and analysis of factors affecting success. J Shoulder Elbow Surg 2012;21:1443-9.

9. Singh S, Yong CK, Mariapan S. Closed reduction techniques in acute anterior shoulder dislocation: modified Milch technique compared with traction-countertraction technique. J Shoulder Elbow Surg 2012;21:1706-11.

10. Nordqvist A, Petersson CJ. Incidence and causes of shoulder girdle injuries in an urban population. J Shoulder Elbow Surg 1995;4:107-12.

11. Robinson CM, Shur N, Sharpe T, et al. Injuries associated with traumatic anterior glenohumeral dislocations. J Bone Joint Surg Am 2012;94:18-26.

12. Liavaag $S$, Svenningsen $S$, Reikerås $\mathrm{O}$, et al. The epidemiology of shoulder dislocations in Oslo. Scand J Med Sci Sports 2011;21:e334-e340.

13. te Slaa RL, Wijffels MP, Brand R, et al. The prognosis following acute primary glenohumeral dislocation. $J$ Bone Joint Surg Br 2004;86:58-64.

14. Leroux $T$, Wasserstein $D$, Veillette $C$, et al. Epidemiology of primary anterior shoulder dislocation requiring closed reduction in Ontario, Canada. Am J Sports Med 2014;42:442-50.

15. Krøner K, Lind T, Jensen J. The epidemiology of shoulder dislocations. Arch Orthop Trauma Surg 1989;108:288-90.

16. Robinson CM, Seah M, Akhtar MA. The epidemiology, risk of recurrence, and functional outcome after an acute traumatic posterior dislocation of the shoulder. J Bone Joint Surg Am 2011;93:1605-13.

17. Simonet WT, Melton LJ, Cofield RH, et al. Incidence of anterior shoulder dislocation in Olmsted County, Minnesota. Clin Orthop Relat Res 1984:186-91.

18. Cunningham NJ. Techniques for reduction of anteroinferior shoulder dislocation. Emerg Med Australas 2005;17:463-71.

19. Pishbin E, Bolvardi E, Ahmadi K. Scapular manipulation for reduction of anterior shoulder dislocation without analgesia: results of a prospective study. Emerg Med Australas 2011;23:54-8.

20. Robers JR WB, Saunders HJ. Roberts \& Hedges' Clinical Procedures in Emergency Medicine. 5th edn: Elsevier.

21. Theivendran K, Dwan K. closed reduction methods for acute anterior shoulder dislocation. Cochrane Database Syst Rev Doi: 10.1002/14651858.CD011051.

22. Riebel GD, McCabe JB. Anterior shoulder dislocation: a review of reduction techniques. Am J Emerg Med 1991;9:180-8.

23. Mattick A, Wyatt JP. From Hippocrates to the Eskimo-a history of techniques used to reduce anterior dislocation of the shoulder. $J R$ Coll Surg Edinb 2000;45:312-6.

24. Ufberg JW, Vilke GM, Chan TC, et al. Anterior shoulder dislocations: beyond traction-countertraction. J Emerg Med 2004;27:301-6.

25. Stimson LA. An easy method of reducing dislocations of the shoulder and hip. Med. Rec 1900;57:356-7.

26. Manes HR. A new method of shoulder reduction in the elderly. Clin Orthop Relat Res 1980:200-202.

27. Janecki CJ, Shahcheragh GH. The forward elevation maneuver for reduction of anterior dislocations of the shoulder. Clin Orthop Relat Res 1982:177-80. 
28. Poulsen SR. Reduction of acute shoulder dislocations using the Eskimo technique: a study of 23 consecutive cases. J Trauma 1988;28:1382-3.

29. Eachempati KK, Dua A, Malhotra R, et al. The external rotation method for reduction of acute anterior dislocations and fracturedislocation of the shoulder. J Bone Jt. Surg Am 2004;86:2431-4.

30. Westin CD, Gill EA, Noyes ME, et al. Anterior shoulder dislocation. A simple and rapid method for reduction. Am J Sports Med 1995;23:369-71.

31. Ceroni D, Sadri H, Leuenberger A. Anteroinferior shoulder dislocation: an auto-reduction method without analgesia. $J$ Orthop Trauma 1997;11:399-404.

32. Yuen MC, Yap PG, Chan YT, et al. An easy method to reduce anterior shoulder dislocation: the Spaso technique. Emerg Med J 2001;18:370-2.

33. Ugras AA, Mahirogullari M, Kural C, et al. Reduction of anterior shoulder dislocations by Spaso technique: clinical results. J Emerg Med 2008;34:383-7.

34. Caudevilla Polo S, Estébanez de Miguel E, Lucha López O, et al. Humerus axial traction with acromial fixation reduction maneuver for anterior shoulder dislocation. J Emerg Med 2011;41:282-4.

35. Chung JY, Cheng CH, Graham CA, et al. The effectiveness of a specially designed shoulder chair for closed reduction of acute shoulder dislocation in the emergency department: a randomised control trial. Emerg Med J 2013;30:795-800.

36. Pallin DJ. SOSMAT: single-operator scapular manipulation and traction-countertraction for reduction of anterior shoulder dislocation. J Emerg Med 2013;44:486-8.

37. Turturro F, Montanaro A, Calderaro C, et al. Efficacy of the assisted self-reduction technique for acute anterior shoulder dislocation. Arch Orthop Trauma Surg 2014;134:1761-5.

38. Uglow MG. Kocher's painless reduction of anterior dislocation of the shoulder: a prospective randomised trial. Injury 1998;29:135-7.

39. Chong M, Karataglis D, Learmonth D. Survey of the management of acute traumatic first-time anterior shoulder dislocation among trauma clinicians in the UK. Ann R Coll Surg Engl 2006;88:454-8.

40. O'Connor DR, Schwarze D, Fragomen AT, et al. Painless reduction of acute anterior shoulder dislocations without anesthesia. Orthopedics 2006;29:528-32.

41. Fernández-Valencia JA, Cuñe J, Casulleres JM, et al. The Spaso technique: a prospective study of 34 dislocations. Am J Emerg Med 2009;27:466-9.

42. Regauer M, Polzer H, Mutschler W. Neurovascular complications due to the Hippocrates method for reducing anterior shoulder dislocations. World J Orthop 2014;5:57-61.

43. Hussein MK. Kocher's method is 3,000 years old. J Bone Joint Surg Br 1968;50:669-71.

44. Beattie TF, Steedman DJ, McGowan A, et al. A comparison of the Milch and Kocher techniques for acute anterior dislocation of the shoulder. Injury 1986;17:349-52.

45. Milch $\mathrm{H}$. Treatment of dislocation of the shoulder. Surgery 1938;3:732-40.

46. Dudkiewicz I, Arzi H, Salai M, et al. Patients education of a selfreduction technique for anterior glenohumeral dislocation of shoulder. J Trauma 2010;68:620-3.

47. Russell JA, Holmes EM, Keller DJ, et al. Reduction of acute anterior shoulder dislocations using the Milch technique: a study of ski injuries. J Trauma 1981;21:802-4.

48. Johnson G, Hulse W, McGowan A. The Milch technique for reduction of anterior shoulder dislocations in an accident and emergency department. Arch Emerg Med 1992;9:40-3.

49. Kirker JR. Dislocation of the shoulder complicated by rupture of the axillary vessels. J Bone Joint Surg Br 1952;34:72-3.

50. Nash J. The status of Kocher's method of reducing recent anterior dislocation of the shoulder. 1934;16.

51. Atoun E, Narvani A, Even T, et al. Management of first-time dislocations of the shoulder in patients older than 40 years: the prevalence of iatrogenic fracture. J Orthop Trauma 2013;27:190-3.

52. Hersche $\mathrm{O}$, Gerber $\mathrm{C}$. latrogenic displacement of fracturedislocations of the shoulder. A report of seven cases. J Bone Jt. Surg Br 1994;76:30-3

53. Garnavos C. Technical note: modifications and improvements of the Milch technique for the reduction of anterior dislocation of the shoulder without premedication. J Trauma 1992;32:801-3.

54. Cunningham $\mathrm{N}$. A new drug free technique for reducing anterior shoulder dislocations. Emerg Med 2003;15:521-4.

55. Kothari RU, Dronen SC. The scapular manipulation technique for the reduction of acute anterior shoulder dislocations. J Emerg Med 1990;8:625-8.

56. Anderson D, Zvirbulis R, Ciullo J. Scapular manipulation for reduction of anterior shoulder dislocations. Clin Orthop Relat Res 1982:181-3.
57. Trimmings NP. Haemarthrosis aspiration in treatment of anterior dislocation of the shoulder. J $R$ Soc Med 1985;78:1023-7.

58. Suder PA, Mikkelsen JB, Hougaard K, et al. Reduction of traumatic secondary shoulder dislocations with lidocaine. Arch Orthop Trauma Surg 1995;114:233-6.

59. Gleeson AP, Graham CA, Meyer AD. Intra-articular lignocaine versus Entonox for reduction of acute anterior shoulder dislocation. Injury 1999;30:403-5.

60. Gleeson AP, Graham CA, Jones I, et al. Comparison of intra-articular lignocaine and a suprascapular nerve block for acute anterior shoulder dislocation. Injury 1997;28:141-2.

61. Kosnik J, Shamsa F, Raphael E, et al. Anesthetic methods for reduction of acute shoulder dislocations: a prospective randomized study comparing intraarticular lidocaine with intravenous analgesia and sedation. Am J Emerg Med 1999;17:566-70.

62. Burton JH, Bock AJ, Strout TD, et al. Etomidate and midazolam for reduction of anterior shoulder dislocation: a randomized, controlled trial. Ann Emerg Med 2002;40:496-504.

63. Miller SL, Cleeman E, Auerbach J, et al. Comparison of intraarticular lidocaine and intravenous sedation for reduction of shoulder dislocations: a randomized, prospective study. J Bone Joint Surg Am 2002;84:2135-9.

64. Orlinsky M, Shon S, Chiang C, et al. Comparative study of intraarticular lidocaine and intravenous meperidine/diazepam for shoulder dislocations. J Emerg Med 2002;22:241-5.

65. Taylor DM, O'Brien D, Ritchie P, et al. Propofol versus midazolam/ fentanyl for reduction of anterior shoulder dislocation. Acad Emerg Med 2005;12:13-19.

66. Dunn MJ, Mitchell R, Souza CD, et al. Evaluation of propofol and remifentanil for intravenous sedation for reducing shoulder dislocations in the emergency department. Emerg Med $J$ 2006;23:57-8.

67. Fitch RW, Kuhn JE. Intraarticular lidocaine versus intravenous procedural sedation with narcotics and benzodiazepines for reduction of the dislocated shoulder: a systematic review. Acad Emerg Med 2008;15:703-8.

68. Blaivas M, Adhikari S, Lander L. A prospective comparison of procedural sedation and ultrasound-guided interscalene nerve block for shoulder reduction in the emergency department. Acad Emerg Med 2011;18:922-7.

69. Cheok CY, Mohamad JA, Ahmad TS. Pain relief for reduction of acute anterior shoulder dislocations: a prospective randomized study comparing intravenous sedation with intra-articular lidocaine. $J$ Orthop Trauma 2011;25:5-10.

70. Mahshidfar B, Asgari-Darian A, Ghafouri HB, et al. Reduction of anterior shoulder dislocation in emergency department; is entonox(®) effective? Bioimpacts 2011;1:237-40.

71. Wakai A, O'Sullivan R, McCabe A. Intra-articular lignocaine versus intravenous analgesia with or without sedation for manual reduction of acute anterior shoulder dislocation in adults. Cochrane Database Syst Rev CD 2011.

72. Waterbrook AL, Paul S. Intra-articular lidocaine injection for shoulder reductions: a clinical review. Sports Health 2011;3:556-9.

73. Jiang $\mathrm{N}, \mathrm{Hu} \mathrm{YJ}$, Zhang KR, et al. Intra-articular lidocaine versus intravenous analgesia and sedation for manual closed reduction of acute anterior shoulder dislocation: an updated meta-analysis. J Clin Anesth 2014;26:350-9

74. Tezel O, Kaldirim U, Bilgic S, et al. A comparison of suprascapular nerve block and procedural sedation analgesia in shoulder dislocation reduction. Am J Emerg Med 2014;32:549-52.

75. Hames H, McLeod S, Millard W. Intra-articular lidocaine versus intravenous sedation for the reduction of anterior shoulder dislocations in the emergency department. can. J. Emerg. Med 2011;13:378-83.

76. Descamps MJ, Gwilym S, Weldon D, et al. Prospective audit of emergency department transit times associated with entonox analgesia for reduction of the acute, traumatic dislocated shoulder. Accid Emerg Nurs 2007;15:223-7.

77. Dunn MJ, Mitchell R, DeSouza Cl, et al. Recovery from sedation with remifentanil and propofol, compared with morphine and midazolam, for reduction in anterior shoulder dislocation. Emerg Med J 2011;28:6-10.

78. Chalidis B, Sachinis N, Dimitriou C, et al. Has the management of shoulder dislocation changed over time? Int Orthop 2007;31:385-9.

79. Maity A, Roy DS, Mondal BC. A prospective randomised clinical trial comparing FARES method with the Eachempati external rotation method for reduction of acute anterior dislocation of shoulder. Injury 2012;43:1066-70.

80. Kothari RU, Dronen SC. Prospective evaluation of the scapular manipulation technique in reducing anterior shoulder dislocations. Ann Emerg Med 1992;21:1349-52. 